\title{
Sobre la "Biografía y Crítica" de Francisco Pimentel
}

Poco conocida es la Biografía y crítica de los principales poetas en 1869 en la Imprenta de F. Díaz de León y Santiago White y que no pasó de la página 72 , interrumpiéndose en la mitad del estudio de Anastasio María de Ochoa.

No sé cuántos ejemplares de este libro existen. Hay uno en la biblioteca de la Universidad de Illinois y otro en mi biblioteca particular. El libro tiene los mismos formato y fecha que El Renacimiento y en ambos casos está encuadernado con el segundo tomo de dicha revista.

Una rápida comparación de la Biografía con la Historia crítica de la poesía en México, en los tomos $\mathrm{rv}$ y $\mathrm{v}$ de las Obras completas (1903-04) de Pimentel, nos muestra que casi todo el contenido de la Biografía se halla en la Historia. La comparación detallada de las dos obras revela algo sobre los métodos y propósitos de don Francisco.

Señalemos primero el contenido de la Biografía. Empieza con una "Introducción" dividida en dos partes: "I. Objeto e importancia de las bellas artes, principalmente de la poesía", pp. 3-8, y "II. Utilidad de la critica. Observaciones sobre este libro", pp. 8-10. Siguen las biografías y crítica de Sor Juana Inés de la Cruz, pp. 11-30, del presbítero don José Manuel Sartorio, pp. 31-39, ${ }^{1}$ de fray Manuel Navarrete, pp. 45-65, y del presbítero don Anastasio María de Ochoa, pp. 67-72.

La introducción de la Biografía reaparece en la Historia en la misma forma, excepto que la última parte, "Observaciones sobre 
este-libro", no se repitió, pues lo que ahí decía Pimentel no podía aplicarse al libro más amplio que después publicó. Las materias de las demás partes de la Biografía, salvo unas pequeñas secciones que comentaremos abajo, corresponden de la siguiente manera a las divisiones de la Historia:

\section{Biografía}

Sor Juana, vi partes

Sartorio, IV partes

Navarrete, IV partes

Ochoa, II partes (inconcluso)

\section{Historia}

Cap. v

Cap. viII

Cap. IX

Cap. XI

Los últimos párrafos de la segunda parte del estudio sobre Sartorio reaparecen, no en la Historia, sino en el cap. VII, pp. 397-98, de Novelistas y oradores mexicanos, $\mathrm{t}$. $\mathrm{v}$ de las Obras, por tener que ver con la oratoria sagrada.

La parte vi de la sección dedicada a Navarrete, que trae el título "Sor Juana Inés de la Cruz, Sartorio, Navarrete", no reaparece, que yo sepa, en ninguna parte de las obras de don Francisco. Es esto algo extraordinario porque mientras más se estudia estas dos obras, más claro se ve que, a pesar de un lapso de dieciséis años entre 1869 y 1885, año el último en que se publicó por primera vez la Historia, no deja Pimentel de hacer uso de todo lo que escribió antes. Por otra parte, este procedimiento tiene alguna utilidad, pues la importancia de este escritor se halla no en su crítica sino en el acopio de datos que nos dejó.

En la Biografía hay un número bastante grande de citas de poesías que Pimentel no juzgó necesario incluir en la Historia. Se trata siempre de poesías no acompañadas de juicios críticos.

Por lo demás, las diferencias en los textos de ambos libros son de tres clases: 1) el cambio infrecuente de una palabra o de palabras en el intento de mejorar el estilo; 2) el agregado de unos renglones más, al final de párrafos y a veces la intercalación de párrafos enteros; y 3) la adición de las notas finales, en ciertos capítulos de la Historia.

Sería una injusticia decir que Pimentel no cambiaba de opinión; pero parece haberla modificado con mucha pena, por desperdiciar 
la idea que antes había tenido. Por ejemplo en la Biografía, p. 53, hablando de la poesía, "Calle la fama ahora", de Navarrete, dice don Francisco: "Un solo lunar tiene para nosotros la composición de que vamos hablando, y es el adjetivo blanda aplicado a Venus: hubiera quedado muy bien blonda, porque Venus ha sido representada algunas veces con cabello de color rubio negligentemente rizado por detrás." Repite esto Pimentel en su Historia (Obras, t. Iv, p. 316), pero añade una oración más al párrafo: "Acaso blanda sea errata de imprenta."

Cuando Pimentel empezó este trabajo, parece que tenía un propósito muy diferente de aquel con que acabó. Dice Pedro Santacilia en su libro Del movimiento literario en México (1868, p. 85): "Ha empezado La constitución social a insertar en su folletín una obra de don Francisco Pimentel, que lleva por título Biografía y crítica de los principales escritores mexicanos desde el siglo XVI hasta nuestros dias, y ya en lo que va publicado del primer capítulo, se ocupa el autor de la célebre poetisa Sor Juana Inés de la Cruz."

Muy poco tardó Pimentel en convencerse de que era demasiado amplio el asunto, para el libro que se proponía escribir, pues encontramos las siguientes líneas, en el final de la introducción de su libro trunco de 1869 (p. 10): "E1 otro punto de que nos restaba hablar es sobre el título del presente libro, el cual comenzó a publicarse en el periódico La constitución social, bajo el nombre de 'Biografía y crítica de los principales escritores mexicanos, desde el siglo XvI hasta nuestros días.' Después hemos creído conveniente dividirle en dos partes, una que trata de los poetas y otra de los prosistas, lo cual explica el título de la primera parte, que es la que ahora ve la luz pública." 2

¿Sería posible que se quedara trunca la Biografía porque otra vez Pimentel cambió de plan? El caso es que cuando apareció en la forma final, el autor usó casi todo el contenido del primer libro en la Historia, con la añadidura de capítulos que incluyen la historia poética antigua y la que mediaba entre los poetas ya discutidos, trayendo el asunto finalmente hasta los poetas muertos en las décacas del '70 al ' 89.

En cuanto a los demás autores que había pensado incluir en el estudio original sobre los "principales escritores", los dejó evidente- 
mente para su libro Novelistas y oradores, publicado póstumamente por sus hijos.

\author{
Ralph E. Warner, \\ Universidad de Colorado.
}

\title{
$\mathrm{N} O \mathrm{~T}$ A S
}

1 Están mal numeradas las signaturas y las páginas de este libro. Hay dos signaturas numeradas "10", cada una con paginación 37-40. En la segunda página 39 termina el estudio de Sartorio. Está en blanco la segunda página [40]. El estudio de Navarrete empieza en la signatura 12 y la página 45, por lo que se ve que el impresor notó la duplicación de números en las páginas de la que debía ser la signatura 11, la corrigió en la signatura 12 sin tocar en la anterior. El texto es continuo.

2 Añade Pimentel que vieron la luz en $L a$ constitución social los artículos sobre Sor Juana y Sartorio y una parte del estudio de Navarrete. Será éste mo de los innumerables folletines perdidos del siglo pasado en México. 